\title{
Diagnostic accuracy of squash cytology in central nervous system tumors
}

\author{
Shrestha Ram Kumar ${ }^{1}$ KC Bibek ${ }^{2}$, Sedain Gopal ${ }^{1}$, Sayami Gita ${ }^{2}$, Shilpakar Sushil ${ }^{1}$, Sharma Mohan Raj ${ }^{1}$, \\ Pradhanang Amit Bahadur', Kafle Prakash ${ }^{1}$, Rajbhandari Binod ${ }^{1}$
}

${ }^{1}$ Department of Neurosurgery, Tribhuvan University Teaching Hospital (TUTH)

${ }^{2}$ Department of Pathology, TUTH

Correspondence: Dr Ram Kumar Shrestha, Resident: Department of Neurosurgery, TUTH

Email: recti90@gmail.com

\begin{tabular}{l} 
Abstract \\
\hline \hline Introduction: CNS tumor requires intraoperative decision making regarding the extent of tumor \\
removal. Clinical examination and imaging studies are not sufficient enough to predict the biological \\
behavior of the tumors. Squash cytology is a quick method of evaluation of cytomorphologic features \\
prepared from smear technique and provide the preliminary diagnosis and aid in intraoperative \\
decision making by differentiating neoplastic from non neoplastic and benign from malignant \\
lesions. The aim of this study is compare the diagnostic accuracy of squash cytology to that of \\
histopathological examination. \\
Methods: This study consists of 36 specimens from both brain and spine subjected to both squash \\
cytology and histopathological evaluation. The squash preparation and histopathological finding \\
were later compared and diagnostic accuracy calculated. \\
Results: Gliomas are the most common tumor encountered and the accuracy of Squash cytology \\
obtained was $71 \%$. In meningioma, $100 \%$ diagnostic accuracy was obtained however, there was \\
limitation in accurately predict the subgroup of tumor by squash cytology alone. Other neoplastic \\
lesions included in this study were Schwannoma, Oligodendroglioma, Ependymoma, mixed tumors \\
and others. Overall, the accuracy predicted by squash cytology is found to be $77.8 \%$ in this study. \\
Conclusion: Squash cytology is rapid and reliable method of tissue diagnosis that aid in intraoperative \\
decision making regarding the extent of Central Nervous System tumor excision \\
\hline \hline
\end{tabular}

\section{Introduction}

Central nervous system (CNS) tumors comprise of brain and spinal cord tumors with varying clinical signs and symptomatology, as well as, imaging characteristics. The tumors can range from truly benign to overt malignant; however, the pathological differentiations from clinical and radiological parameters is often confusing ${ }^{1,2}$ At times, intraoperative decision-making can be difficult due to the tumor location, pre-operative and anticipated neurological deficits. Incomplete resection of benign pathology can deny patient with the chance for cure. However, overzealous attempt for complete resection in a patient with malignant pathology can increase neurological deficits and surgical morbidity and decrease quality of life without increasing survival benefit. ${ }^{3}$
Squash cytology (SC) is a method of quick evaluation of cytomorphologic features prepared from smear technique that could provide the preliminary diagnosis, separating the low grade tumors from the high grade ones as well as differentiating non-neoplastic from neoplastic lesions., ${ }^{4,5,6}$ Unnecessary surgeries can be avoided in non-neoplastic lesions. As such, it can distinguish tumors amenable to gross total resection (i.e. Ependymoma) from tumors that are not (i.e. Germinoma); and it also enables tissue allocation for tumor banking, molecular testing, culture or other ancillary techniques. ${ }^{7,8,9}$ Previous studies have correlated the diagnostic efficacy of SC with formal histopathological (HP) evaluation. It has been found to be as high as $85 \%$. 
Few studies have been done in India but to the best of our knowledge, no such study has been yet carried out in our country. Hence, this study was undertaken to correlate cytomorphological diagnosis by squash smear technique to that of histopathological examination of CNS neoplastic lesions and to determine the diagnostic accuracy of SC.

\section{Methods}

This study was conducted over a period of five months from November 2015 to March 2016 at the Departments of Neurosurgery and Pathology in Tribhuvan University Teaching Hospital. There were a total of 36 cases of CNS neoplastic lesions, who had both SC and HP evaluation. The tumor tissue obtained during the time of surgery was separated into two specimens. Specimen one was promptly transported in isotonic normal saline and sent for SC while the specimen two was fixed and transported in $10 \%$ formalin at the end of surgery for HP evaluation. The specimen for SC was squash smeared and 4 Giemsa stain and 2 pap stain were prepared and evaluated. Relevant clinical and radiological data were recorded. Cytological and HP findings were recorded separately. Final comparison between HP observations and SC impressions was made. Correlation between these two techniques was graded as complete agreement, partial agreement or no agreement (i.e. disagreement). Complete agreement was defined as complete concordance with tumor classification and grading. If the SC could pin point the tumor but failed to grade it, was regarded as a partial agreement. Disagreement or no agreement meant complete misinterpretation in the $\mathrm{SC}$ reports compared to HP evaluation.

\section{Results}

A total of 53 operations were performed for CNS neoplasms over the period of five months. Thirty-seven patient specimen were subjected for SC and HP evaluation, however, only 36 specimens were available for analysis as one patient biopsy specimen was misplaced.

The mean age of the patients was $40.2( \pm 20.9)$ years, theage ranging from 4 to 72 years. In regard to gender, there were 19 females and 17 males. Thirty-one specimens were from brain and 5 from spine.

The SC and HP evaluation of all 36 specimens are represented in detail in Table 1.
Table1: Comparative reports of histopathological examination and squash cytology

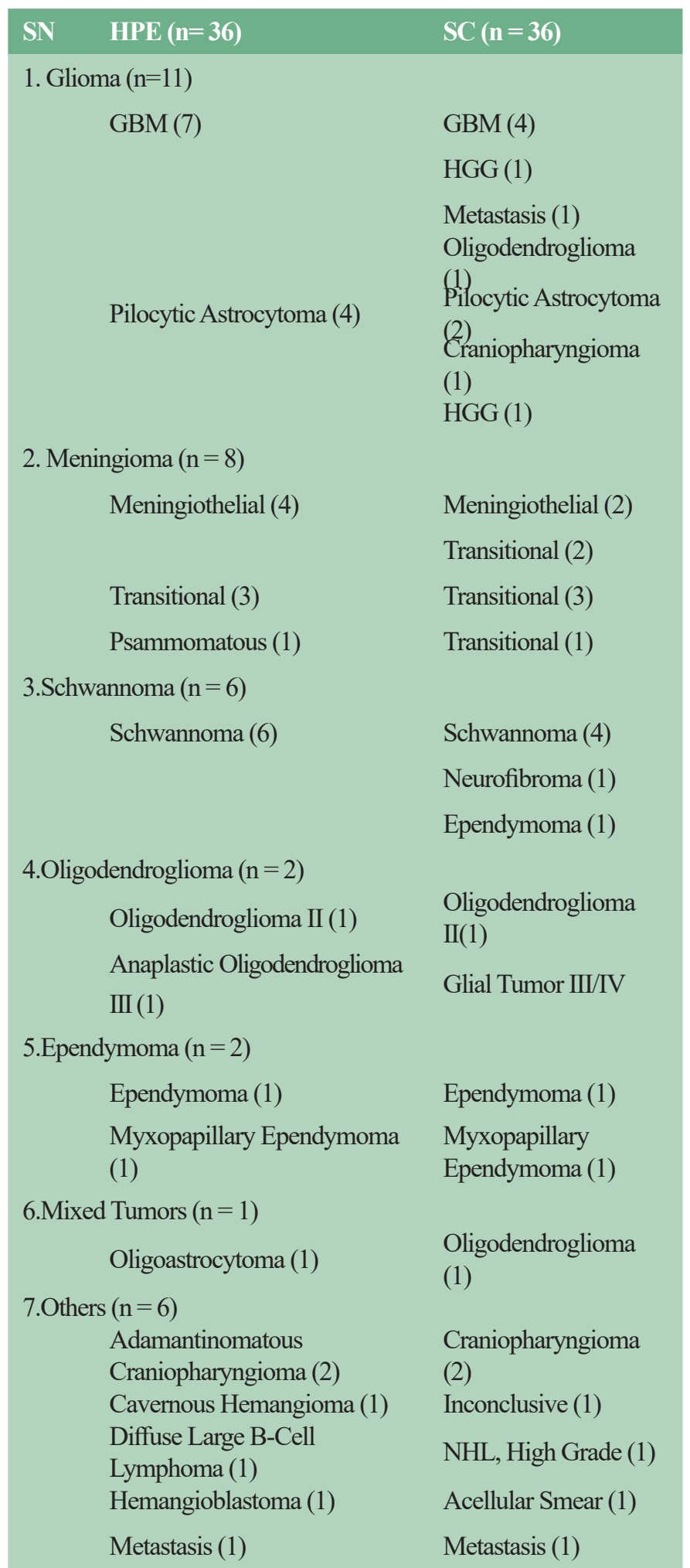


The CNS neoplasms are heterogeneous. ${ }^{2}$ The tumors both benign and malignant were included (Table 1). Overall, glioma was the most commonly-encountered tumor in the studied population, constituting of $30.5 \%$ of the final diagnosis. High grade glioma (HGG) included World Health Organization (WHO) grading III and IV of Astrocytoma. WHO grade I and II were considered as low grade glioma (LGG). In this study, there were a total of 7 cases of Glioblastoma Multiforme (GBM) leveled as WHO grade IV.

In cases with HGG, complete agreement between $\mathrm{SC}$ and HPE was obtained in four specimens and partial agreement in one specimen. Hence, overall accuracy of SC for HGG was found to be $71.4 \%(5 / 7)$. Similarly, there were four cases with LGG; but SC complete agreement with HPE was obtained in only $50 \%(\mathrm{n}=2)$ and partial agreement in $25 \%(\mathrm{n}=1)$; and, hence, the overall agreement was $75 \%$ (3/4). Figure 1A and 1B shows the cytological features and histopathological features of Glioma.

Among benign brain tumors, meningioma isvery common. There were altogether eight cases of meningioma as reported in the final HPE, accounting for 22.2\% (8/38). Meningothelial $(n=4)$, Transitional $(n=3)$ and Psammomatous $(n=1)$ subtypes of meningioma; all belong to the WHO grade I tumors. The complete agreement was observed in $62.5 \%$; and partial agreement was observed in $37.5 \%$.Fig $2 \mathrm{~A}$ and Fig 2B demonstrates the characteristic cytomorphologic and histopathological features of meningioma.

Other tumors in this study included Schwannoma, Oligodendroglioma, Ependymomaand so forth. Schwannomas included in this study comprises vestibular schwannomas, as well as, spinal schwannomas. For all types of tumors, the complete and partial agreement and disagreement are represented in the following Table 2.
When the agreement was dichotomized only as agreement, which includes complete and partial, or no agreement, there were a total of 28 concordances out of 36 specimens, of comparing SC with final HPE. Thus, on calculating the accuracy of $77.8 \%$ was achieved using SC method.

\section{Discussion}

Intraoperative decision-making may change depending upon the intraoperative impression of CNS tumor texture, consistency, vascularity and so on. The heterogeneity of tumors types, the differing aggressiveness of tumors even in similar classification and new advancement in molecular diagnosis and immunohistochemical printing, renders need for confirmation of the pathology to decide upon the extent of resection. At the same time, acquiring sufficient tissue for such procedures is of paramount importance. ${ }^{8,10}$ Fluid cytology may be used for cystic lesions, but for solid lesions $\mathrm{SC}$ and frozen section are two methods available to the surgeons. SC has several advantages over frozen section, especially in CNS lesions. It provides a rapid and reliable diagnosis, requires small sample size, allows tissue to be preserved for paraffin embedding, needs minimal technical equipment, is less expensive, and gives better cellular detail. Moreover, the high water and fat content and innate fragility of brain tissue leading to freezing artifacts and poor quality frozen sections makes this technique superior to frozen sections. ${ }^{9,10,11}$ Furthermore, impression of nonneoplastic lesions especially infective or inflammatory may allow surgeon to avoid resection near or at eloquent area and prevent neurologic deficit ${ }^{7,12,13}$

The accuracy of SC in this study was found to be 77.8 $\%$, which is in concordance with other studies $(80-97$ $\%)^{4,5,6,13,14,15}$ The differing accuracy in various literatures could be due to the extremely heterogenous nature of the lesions included for analysis. Some have included

Table 2: Correlation of squash cytology with histopathological examination among various tumor groups.

\begin{tabular}{|c|c|c|c|c|c|}
\hline \multirow{2}{*}{ Tumor Group } & \multicolumn{3}{|c|}{ Agreement } & \multirow{2}{*}{ Total } & \multirow[t]{2}{*}{ Accuracy $(\%)$} \\
\hline & Complete & Partial & No & & \\
\hline Craniopharyngioma & 0 & 2 & 0 & 2 & 100 \\
\hline Ependymoma & 2 & 0 & 0 & 2 & 100 \\
\hline Glioma & 6 & 2 & 3 & 11 & 72.7 \\
\hline Hemangioblastoma & 0 & 0 & 1 & 1 & 0 \\
\hline Hemangioma & 0 & 0 & 1 & 1 & 0 \\
\hline Lymphoma & 0 & 1 & 0 & 1 & 100 \\
\hline Meningioma & 5 & 3 & 0 & 8 & 100 \\
\hline Metastasis & 1 & 0 & 0 & 1 & 100 \\
\hline Mixed tumors & 0 & 0 & 1 & 1 & 0 \\
\hline Oligodendroglioma & 1 & 1 & 0 & 2 & 100 \\
\hline \multirow[t]{2}{*}{ Schwannoma } & 4 & 0 & 2 & 6 & 66.7 \\
\hline & 19 & 9 & 8 & 36 & 77.8 \\
\hline
\end{tabular}


inflammatory and infectious, while others have taken spinal lesions as well. In addition, the inability to squash the fibrous lesions and inclusions of such lesions may have influencedthe accuracy in some studies. The relatively low accuracy of SC in our study could possibly be due tothe inclusion of cavernous hemangioma and hemangioblastoma which inherently have low SC accuracy. 3,10

We were able to get $100 \%$ diagnostic accuracy of SC in meningioma. Others have recorded around $83 \%$ agreement. The differencemay be due absence of fibrous meningiomas in our study. Other than fibrous type, the meningioma smear is relatively ease to prepare. It showed variable cellularity, high in syncytial type, low fibrous type. The cells were fairly uniform, arranged in syncytial clusters or in whorls, with eosinophilic cytoplasm and poorly-defined boundaries. The nuclei were oval with delicate chromatin and presence of intranuclear inclusions in some. Psammoma bodies were noted in some cases. ${ }^{1,14,16,17}$ (Fig 2A and 2B)

\section{Figures}

Figure 1A and 1B: Squash Cytology and Histopathological Examination of Glioblastoma Multiforme

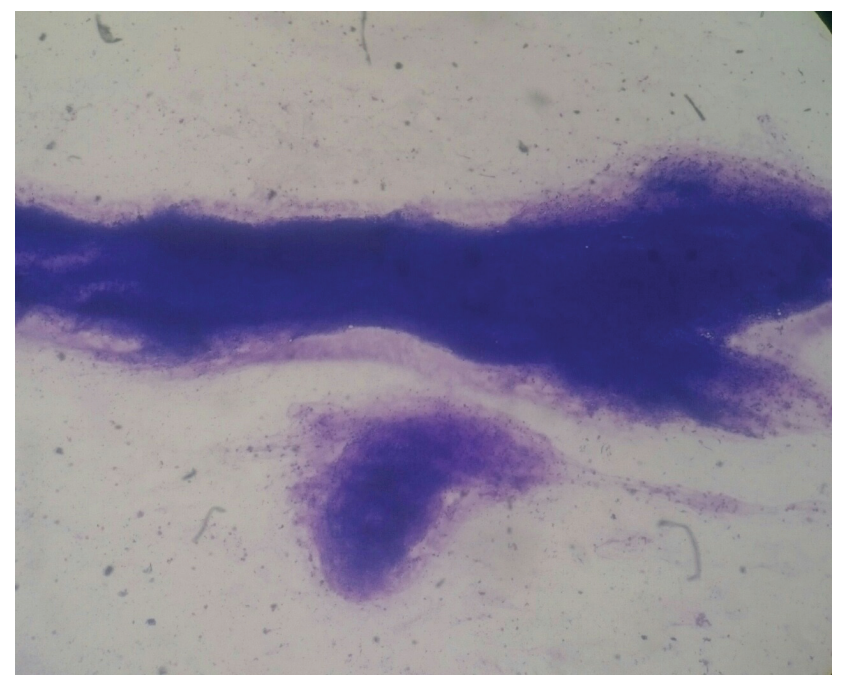

Figure 1A: Squash smear: GBM showing pleomorphic tumor cells in glial background. Occassional bizzare looking cells present and many proliferating capillaries also seen.

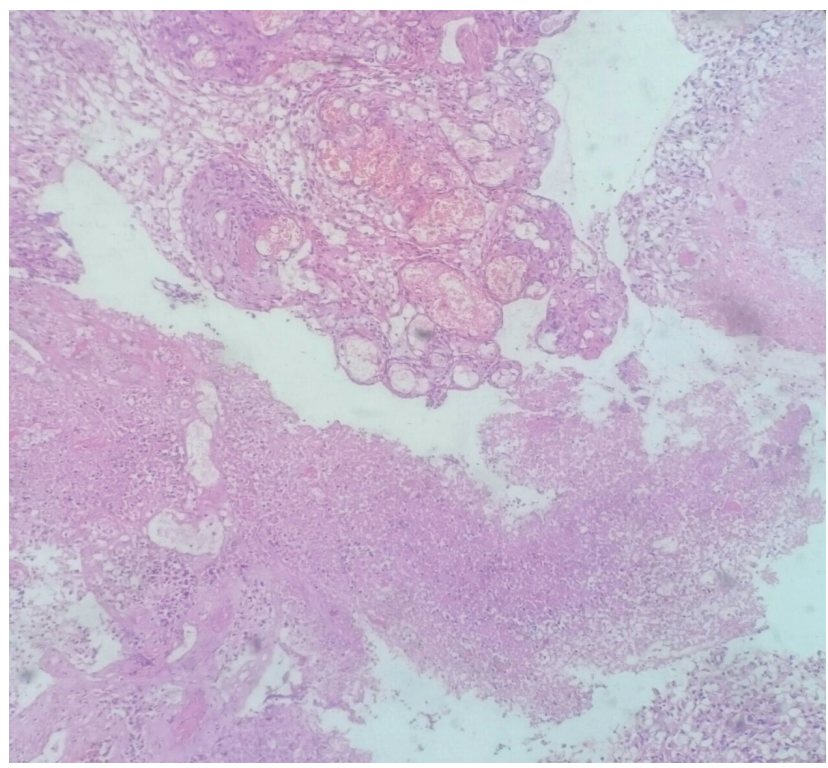

Figure 1 B: Tissue Section GBM: Diffuse proliferation of polygonal to elongated tumor cells with marked pleomorphism. Multiple foci of necrosis and endocapillary proliferation seen.

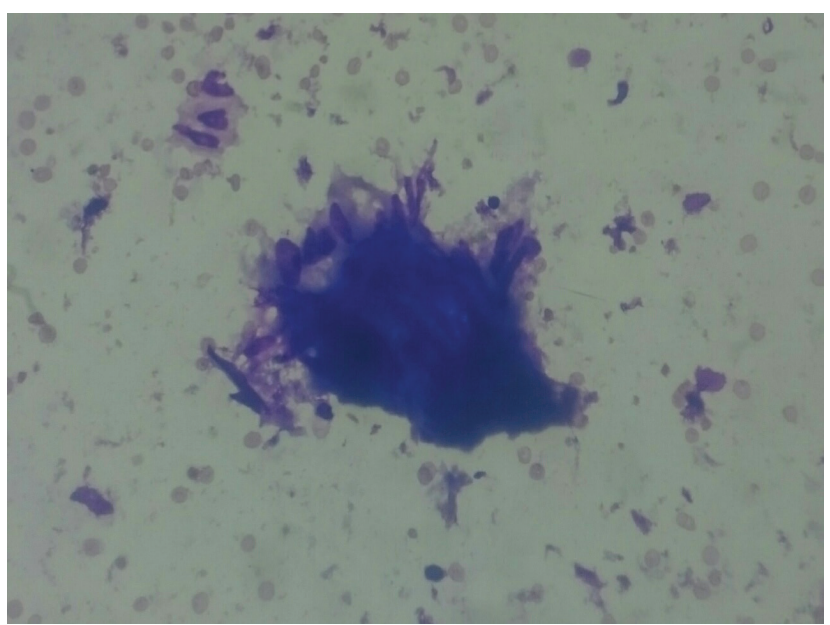

Figure 2Aand2B:Squash Cytology and Histopathological Examination of Transitional Meningioma 


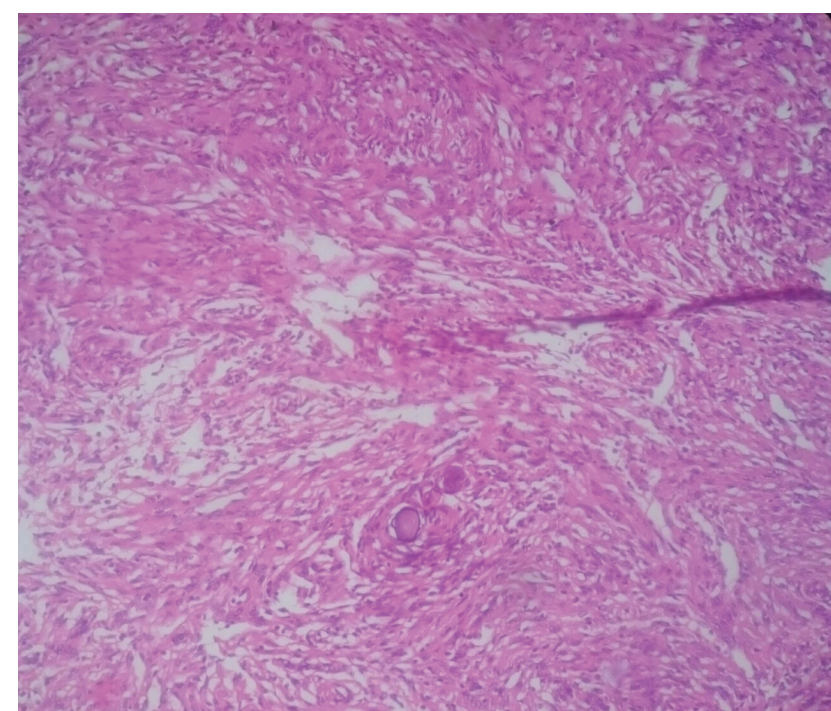

Figure 2A Squash Smear and 2B Tissue section of Transitional Meningioma showing spindle shaped cells having scant cytoplasm with elongated nuclei and inconscipious nucleoli along with meningothelial cells having round to oval nuclei. Psammoma bodies also seen.

Figure 3A and 3B: Squash Cytology of Oligodendroglioma and Histopathological Examination of Oligoastrocytoma

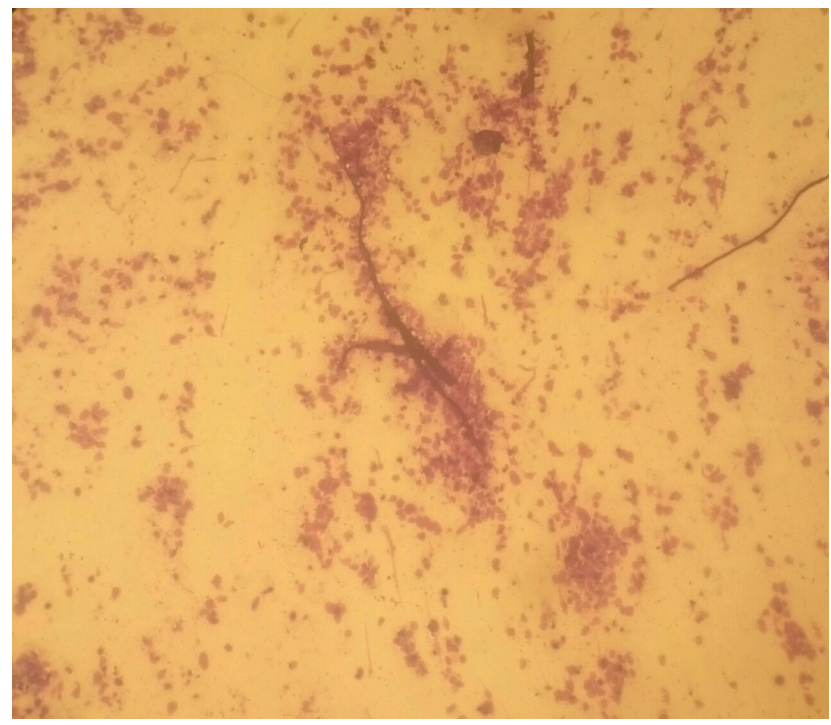

Figure 3A: Squash Smear: Oligodendroglioma showing monomorphic to mildly pleomorphic tumor cells in a glial background with thin walled capillaries.

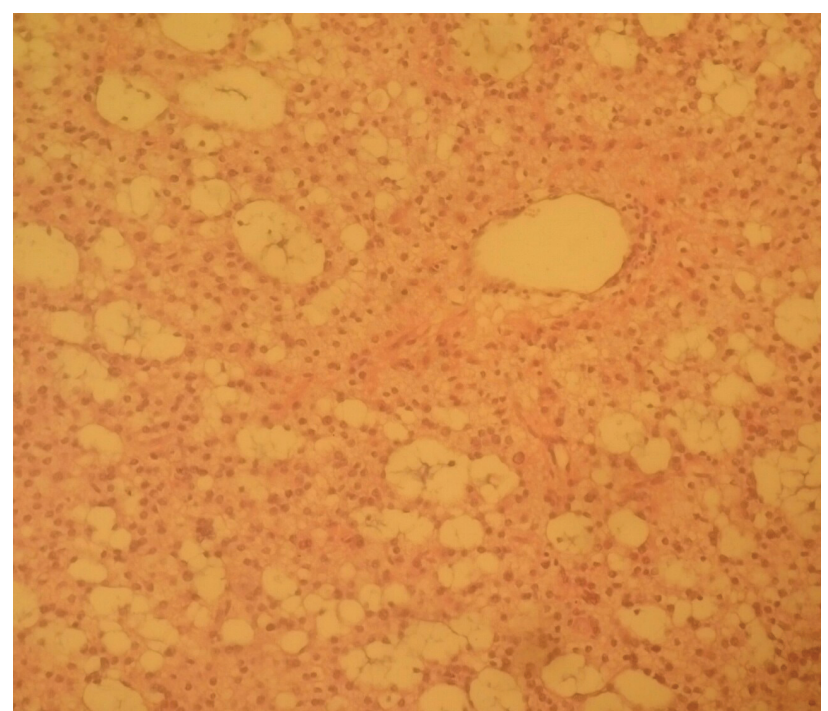

Figure 3B: Tissue Section: Oligoastrocytoma showing diffuse proliferation of tumor cells in fibrillary background showing moderate pleomorphism. Tumor cells are round to oval with irregular nuclei and irregular nuclear rim. Few fragments showing oligodendroglial component composed of monotonus round nuceli and perinuclear halo. Some areas shows microcytic pattern.

In cases of high grade glioma, under grading of lesion is a problem in SC. The fibrillary background common to astrocytoma will be visualized. However, the necrotic tissue (one of the key components of HGG diagnosis) is deliberately left behind during smear preparation. In this study, the accuracy rate of only $63 \%$ for glioma is less than the reported percentage in other studies..$^{5,10,11,13}$ This may be due to the polymorphic nature of HGG itself. The stereotactic biopsy may yield better accuracy in terms of tissue selection for the smear preparation. ${ }^{1,6,14}$ (Fig 1A and 1B)

On the other hand, the tumors, such as ependymoma, oligodendroglioma and mixed tumors had good accuracy as well in concordance with reported elsewhere. The unique features of granular background and microcalcification visible on the smear makes identification of oligodendroglioma easier; but the area from where squash smear is made, might not adequately represent the entire tumor. So, it is not uncommon to see fibrillary background in the histological examination, thus miss the mixed tumors. ${ }^{1,6,15,18,19,20}$ (Fig 3A and Fig 3B) The use of stereotaxy and/or intraoperative Computed Tomography or Magnetic Resonance Imaging may increase the chance of getting into representative area and might have better SC yield. ${ }^{6}$ 


\section{Conclusion}

$\mathrm{SC}$ is a less expensive, reliable and rapid diagnostic method with high accuracy on comparison with final HP evaluation of CNS neoplasm. Intraoperative decision-making regarding the extent of surgical resectionand adequacy of biopsy can be assessed with incorporation of this tool in regular surgical practice of CNS tumors, particularly in developing countries. Further studies with a larger sample size is recommended to explore this technology further.

\section{References}

1. Louis DN, Ohgaki H, Wiestler OD, Cavenee WK, Burger PC, Jouvet A, et al. The 2007 WHO classification of tumours of the central nervous system. Acta neuropathologica. 2007;114(2):97-109. https://doi.org/10.1007/s00401-007-0243-4 PMid:17618441 PMCid:PMC1929165

2. Louis DN, Perry A, Reifenberger G, von Deimling A, Figarella-Branger D, Cavenee WK, et al. The 2016 World Health Organization Classification of Tumors of the Central Nervous System: a summary. Acta neuropathologica. 2016;131(6):803-20. https://doi.org/10.1007/s00401-016-1545-1 PMid:27157931

3. Lacruz CR, Catalina-Fernandez I, Bardales RH, Pimentel J, Lopez-Presa D, Saenz-Santamaria J. Intraoperative consultation on pediatric central nervous system tumors by squash cytology. Cancer cytopathology. 2015;123(6):331-46. https://doi.org/10.1002/cncy.21537 PMid:25766425

4. Iqbal M, Shah A, Wani MA, Kirmani A, Ramzan A. Cytopathology of the central nervous system. Part I. Utility of crush smear cytology in intraoperative diagnosis of central nervous system lesions. Acta cytologica. 2006;50(6):608-16. https://doi.org/10.1159/000326028 PMid: 17152270

5. Mennel HD, Rossberg C, Lorenz H, Schneider H, Hellwig D. Reliability of simple cytological methods in brain tumour biopsy diagnosis. Neurochirurgia. 1989;32(5):129-34. https://doi.org/10.1055/s-2008-1054021

6. Malhotra V, Puri H, Bajaj P. Comparison of smear cytology with histopathology of the CT guided stereotactic brain biopsy. Indian journal of pathology \& microbiology. 2007;50(4):862-4. PMid:18306590
7. Krishnani N, Kumari N, Behari S, Rana C, Gupta P. Intraoperative squash cytology: accuracy and impact on immediate surgical management of central nervous system tumours. Cytopathology : official journal of the British Society for Clinical Cytology. 2012;23(5):308-14. https://doi.org/10.1111/j.1365-2303.2011.00905.x PMid:21838720

8. Moriya J, Tanino MA, Takenami T, Endoh T, Urushido M, Kato Y, et al. Rapid immunocytochemistry based on alternating current electric field using squash smear preparation of central nervous system tumors. Brain tumor pathology. 2016;33(1):13-. https://doi.org/10.1007/s $10014-015-0238-0$ PMid:26546480

9. Pant I, Chaturvedi S. Immunohistochemistry on squash smears: A diagnostic aid. Diagnostic cytopathology. 2010;38(10):780-1. https://doi.org/10.1002/dc.21330

10. Nanarng V, Jacob S, Mahapatra D, Mathew JE. Intraoperative diagnosis of central nervous system lesions: Comparison of squash smear, touch imprint, and frozen section. Journal of cytology / Indian Academy of Cytologists. 2015;32(3):153-8. https://doi.org/10.4103/0970-9371.168835 PMid:26729974 PMCid:PMC4687204

11. Agrawal M, Chandrakar SK, Lokwani D, Purohit MR. Squash cytology in neurosurgical practice: a useful method in resource-limited setting with lack of frozen section facility. Journal of clinical and diagnostic research : JCDR. 2014;8(10):FC09PMid:25478346 PMCid:PMC4253164

12. Sharma N, Misra V, Singh PA, Gupta SK, Debnath S, Nautiya A. Comparative efficacy of imprint and squash cytology in diagnosing lesions of the central nervous system. Asian Pacific journal of cancer prevention : APJCP. 2011;12(7):1693-6. PMid:22126546

13. Jaiswal $\mathrm{S}$, Vij $\mathrm{M}$, Jaiswal AK, Behari $\mathrm{S}$. Intraoperative squash cytology of central nervous system lesions: a single center study of 326 cases. Diagnostic cytopathology. 2012;40(2):104-12. h t tps://doi.org/10.1002/d c.21506 PMid:22246925

14. Goel D, Sundaram C, Paul TR, Uppin SG, Prayaga AK, Panigrahi MK, et al. Intraoperative cytology (squash smear) in neurosurgical practice - pitfalls in diagnosis 
experience based on 3057 samples from a single institution. Cytopathology: official journal of the British Society for Clinical Cytology. 2007;18(5):300-8. https://doi.org/10.1111/j.1365-2303.2007.00484.x PMid:17883691

15. Shah AB, Muzumdar GA, Chitale AR, Bhagwati $\mathrm{SN}$. Squash preparation and frozen section in intraoperative diagnosis of central nervous system tumors. Acta cytologica. 1998;42(5):1149-54. ht tps://doi.org/10.1159/000332104 PMid:9755673

16. Lui PC, Chau TK, Wong SS, Lau PP, Tse GM, Thomas TM, et al. Cytology of chordoid meningioma: a series of five cases with emphasis on differential diagnoses. Journal of clinical pathology. 2007;60(9):1024-8. https://doi.org/10.1136/jcp.2006.040204 PMid:16837627 PMCid:PMC1972413

17. Kobayashi S. Meningioma, neurilemmoma and astrocytoma specimens obtained with the squash method for cytodiagnosis. A cytologic and immunochemical study. Acta cytologica. 1993;37(6):913-22. PMid:8249513

18. Inagawa $\mathrm{H}$, Ishizawa $\mathrm{K}$, Hirose $\mathrm{T}$. Qualitative and quantitative analysis of cytologic assessment of astrocytoma, oligodendroglioma and oligoastrocytoma. Acta cytologica. 2007;51(6):900-6. https://doi.org/10.1159/000325867 PMid:18077983

19. Deb P, Kinra P, Bhatoe HS. Intraoperative cytology of central neurocytoma mimicking oligodendroglioma. Journal of cytology / Indian Academy of Cytologists. 2011;28(4):219-22. https://doi.org/10.4103/0970-9371.86357 PMid:22090702 PMCid:PMC3214473

20. Park JY, Suh YL, Han J. Dysembryoplastic neuroepithelial tumor. Features distinguishing it from oligodendroglioma on cytologic squash preparations. Acta cytologica. 2003;47(4):624-9. ht t p s://doi org/10.1159/000326579 PMid:12920757 